RU Понятийно-категориальный аппарат педагогической теории обеспечения качества профессиональной подготовки иностранных военных специалистов в лётных вузах Воздушно-космических сил

Кузнецов Ю. Н.

\begin{abstract}
Аннотация. Цель исследования - разработать понятия и категории педагогической теории обеспечения качества профессиональной подготовки иностранных военных специалистов в лётных вузах. В статье представлен авторский подход к разработке понятий и категорий педагогической теории обеспечения качества. Научная новизна исследования заключается в том, что в педагогику профессионального образования вводится понятие «обеспечение качества профессиональной подготовки иностранных военных специалистов в лётных вузах». В результате установлена взаимосвязь понятий «подготовка» и «деятельность», а также определяющей категории «обеспечение качества профессиональной подготовки» и категории «профессиональная подготовка», раскрыты особенности и структурные компоненты педагогического процесса обеспечения качества профессиональной подготовки иностранных военных специалистов.
\end{abstract}

\title{
Conceptual-Categorial Apparatus of Methodology to Ensure Quality of Professional Training of Foreign Military Specialists Studying at the Russian Higher Military Aviation School
}

\author{
Kuznetsov Y. N.
}

\begin{abstract}
The research objective is as follows: to develop conceptual-categorial apparatus of methodology to ensure quality of professional training of foreign military specialists studying at the Russian higher military aviation school. The author proposes his own approach to developing conceptual-categorial apparatus of quality assurance methodology. Scientific originality of the study lies in the fact that the researcher introduces the notion “assuring quality of foreign military specialists' professional training at higher military aviation school” into pedagogy of professional education. The research findings are as follows: the author reveals correlation of the notions "training" and "activity", identifies correlation of the categories "professional training quality assurance" and "professional training”, describes the process to ensure quality of foreign military specialists’ professional training.
\end{abstract}

\section{Введение}

Актуальность темы исследования обусловлена значительным влиянием обеспечения качества профессиональной подготовки иностранных военных специалистов (ОК ПП ИВС) в лётных вузах Воздушно-космических сил (BKC) на развитие сферы военно-образовательных услуг, оказываемых Российской Федерацией национальным государствам, что выступает важной научно-практической проблемой военно-педагогической науки, которая характеризуется неоднозначной историко-педагогической ретроспективой [1].

Развитие военной педагогики на современном этапе в направлении ОК ПП ИВС характеризуется чередой организационных преобразований, направленных на «оптимизацию» образовательной деятельности всех её субъектов, результатом которой можно констатировать ухудшение в значительной степени качества профессиональной подготовки. В перечне этих организационных преобразований следует выделить такие негативные 
события, как укрупнение и даже ликвидация ряда военных учебных заведений, потеря военных научных школ и фундаментальных научных направлений, снижение роли специальных факультетов, курирующих профессиональную подготовку ИВС в вузах МО РФ.

Переосмысление и восстановление утраченных позиций обуславливают необходимость в разработке педагогической теории ОК ПП ИВС в лётных вузах ВКС. Важной частной задачей педагогической теории ОК ПП ИВС в лётных вузах ВКС выступает разработка понятийно-категориального аппарата на основе анализа научных источников по теме настоящего исследования [13, с. 122-189; 16; 18; 20, с. 557, с. 1035, 1316]. В рамках настоящего исследования определяющей категорией служит понятие «обеспечение качества профессиональной подготовки» ИВС в лётных вузах ВКС. Таким образом, неоднозначность историко-педагогической ретроспективы ОК ПП ИВС и, как следствие, необходимость повышения качества ПП ИВС в лётных вузах позволяют судить о важности решения проблемы по разработке понятий и категорий педагогической теории ОК ПП ИВС.

Для достижения указанной цели исследования необходимо решить следующие задачи:

- проанализировать научные источники, раскрывающие основные понятия, входящие в предметное поле исследования;

- рассмотреть взаимосвязь определяющей категории «обеспечение качества профессиональной подготовки» и категории «профессиональная подготовка»;

- установить основные особенности ОК ПП ИВС;

- выявить основные компоненты ОК ПП ИВС в лётных вузах ВКС.

Для изучения проблемы ОК ПП ИВС в лётных вузах в статье применяются следующие методы исследования: анализ научной литературы, системно-структурный анализ федерального государственного образовательного стандарта высшего образования лётного профиля и квалификационных требований к профессиональной подготовке выпускников - ИВС лётных вузов.

Теоретической базой исследования послужили федеральный государственный образовательный стандарт высшего образования лётного профиля, квалификационные требования к профессиональной подготовке выпускников - ИВС лётных вузов, «Краткий словарь терминов военного образования» [13], «Советский энциклопедический словарь» [20], сборник научных трудов «Понятийный аппарат педагогики и образования» [16], «Российская педагогическая энциклопедия» [18].

Практическая значимость исследования заключается в возможности использования понятийно-категориального аппарата педагогической теории обеспечения качества профессиональной подготовки ИВС в качестве научно-практической основы при создании в лётных вузах ситуационных центров (отделов) качества военного образования с целью оценки, прогнозирования и коррекции образовательного результата профессиональной подготовки курсантов-лётчиков.

\section{Анализ научных понятий, входящих в предметное поле исследования}

Для решения поставленной цели рассмотрим основные понятия, входящие в предметное поле исследования: «подготовка», «деятельность», «профессиональная подготовка», «обеспечение качества профессиональной подготовки». Согласно имеющимся научным данным понятие «подготовка» аннотируется как «запас полученных знаний» [15, с. 489], в то же время в некоторых источниках «подготовка» рассматривается как «целенаправленный процесс приобретения и упорядочения знаний, умений и навыков по специальности для решения конкретных задач» [19]. Необходимо отметить очевидную взаимосвязь понятий «подготовка» и «профессиональная подготовка». В понятии «профессиональная подготовка», помимо перечисленных черт понятия «подготовка», представлены «социокультурные и профессиональные компоненты» [8, с. 262]. Понятия иерархически взаимосвязаны, причём понятие «подготовка» выступает ключевым понятием по отношению к понятию «профессиональная подготовка» [4]. Большая советская энциклопедия «профессиональную подготовку» представляет как «совокупность специальных знаний, умений и навыков, позволяющих выполнять работу в определённой деятельности» [7].

Проведенное исследование свидетельствует о взаимосвязи понятий «подготовка» и «деятельность». Понятие «деятельность» рассматривается как «совокупность внутренней (мышления) и внешней (труда) активности субъекта, регулируемая сознаваемой целью, управляемое сознанием последовательное выполнение внутренних (мыслительных) и внешних (трудовых) познавательных и преобразовательных функций, осуществляется по определённому алгоритму и реализуется как процесс взаимодействия этих функций в интересах решения профессиональных задач» [17, с. 102; 21, с. 114]. В исследовании речь идёт о подготовке ИВС к лётной деятельности в авиации национальных государств.

В соответствии с имеющимися научными данными профессиональная деятельность характеризуется профессиональной средой и эффективностью её осуществления в определённых условиях. В лётных вузах это определяют квалификационные требования (КТ), предъявляемые к выпускнику - ИВС по решению задач лётной деятельности.

ПП ИВС в лётных вузах ВКС как явление можно рассматривать двояко: 1) как «единый целенаправленный процесс воспитания и обучения» [14]; 2) как «подход к выделению основных и взаимосвязанных задач образования, воспитания и подготовки» [6, с. 53]. Если рассматривать ПП ИВС в лётных вузах ВКС 
как педагогический процесс, то сущность процесса ОК ПП ИВС можно характеризовать с двух позиций: 1) уровня сформированности интеллектуально-личностных качеств; 2) уровня сформированности профессиональных компетенций.

Таким образом, анализ научных источников показывает, что для исследования ПП в военных вузах в большей степени используются системный, процессуальный и результативный методы. В то же время в психологопедагогических исследованиях широко используется системно-структурный метод как общенаучный метод, который при анализе ПП в лётных вузах не нашел реального применения. Следует констатировать, что применение системно-структурного метода в анализе ПП актуализирует поиск инновационных направлений в исследовании структурно-содержательной характеристики данной категории.

\section{Взаимосвязь определяющей категории «обеспечение качества профессиональной подготовки» и категории «профессиональная подготовка»}

Важным аспектом изучаемого в настоящем исследовании явления в рамках понятийно-категориального аппарата следует рассматривать взаимосвязь определяющей категории «обеспечение качества профессиональной подготовки» и категории «профессиональная подготовка». Взаимосвязь однозначно устанавливается через определение категорий, которые формулируются ниже. ПП призвана осуществлять формирование интеллектуально-личностных качеств и профессиональных компетенций ИВС, необходимых для эффективной лётной деятельности в авиации национальных Вооруженных Сил.

Анализ КТ к военно-профессиональной подготовке выпускников в лётных вузах ВКС позволяет констатировать необходимость наличия у выпускников - ИВС различных родов авиации восьми профессиональных компетенций:

- готовности применять штатное оружие, способности управлять огнём подразделения, умения проведения занятий по предметам боевой подготовки (ПК-25);

- способности использовать военно-исторический опыт при выработке решений на выполнение поставленной задачи (ПК-26);

- способности к оценке, прогнозированию обстановки и принятию решений на выполнение боевых задач (ПК-27);

- готовности к выполнению задач мирного и военного времени (ПК-28);

- способности к применению навыков физической подготовки (ПК-29);

- готовности применять знания нормативных правовых документов в сфере военно-профессиональной деятельности (ПК-30);

- способности представлять положение воздушного судна по показаниям приборов, а также по восприятию неинструментальных сигналов в опорных точках (ПК-31);

- способности к выполнению полёта и обеспечению его безопасности в штурманском отношении (ПК-32).

Если исходить из настоящей трактовки категории ПП, то данное понятие в общем виде можно рассматривать как педагогический процесс ОК ПП российских и национальных военных специалистов.

Таким образом, на основе анализа литературных источников по теме настоящего исследования представляется возможным дать следующую формулировку этому понятию: «ОК ПП ИВС в лётных вузах ВКС - целенаправленный и организованный процесс инновационного улучшения качественных параметров профессиональной подготовки военного лётчика». Настоящая формулировка только в общем плане раскрывает содержание этого понятия. Важными характеристиками содержания понятия также выступают особенности и структурные компоненты ОК ПП ИВС.

\section{Основные особенности обеспечения качества профессиональной подготовки иностранных военных специалистов в лётных вузах}

Рассмотрим основные особенности ОК ПП ИВС.

Первая особенность заключается в том, что, с одной стороны, ОК ПП ИВС функционирует как составная часть педагогической системы вуза, а с другой стороны, как педагогический процесс.

Второй особенностью данного понятия выступает комплексность ОК ПП ИВС по трём основным направлениям: 1) наличие комплексных дисциплин; 2) проведение комплексных занятий; 3) проведение комплексных экзаменов. Следует отметить, что все вышеуказанные направления являются приоритетными в ОК ПП ИВС на кафедрах в лётных вузах ВКС.

Третьей особенностью выступают многопрофильность и многоплановость ОК ПП ИВС.

Многопрофильность ОК ПП ИВС характеризуется спецификой основных черт, квалифицирующих лётную деятельность определённого рода авиации. К основным профилям лётной подготовки относятся: истребительная авиация, фронтовая бомбардировочная и штурмовая авиация, дальняя авиация, военно-транспортная авиация, морская ракетоносная и противолодочная авиация. 
Многоплановость ОК ПП ИВС обусловлена двумя причинами:

- реализацией в педагогическом процессе лётного вуза принципа единства обучения, воспитания и психологической подготовки ИВС;

- разнообразием компонентов педагогической деятельности профессорско-преподавательского состава лётных вузов в процессе ОК ПП ИВС [9; 22].

Многоплановость ОК ПП ИВС также характеризуется плановыми и ситуативными педагогическими задачами [3; 5].

Четвёртой особенностью ОК ПП ИВС выступает необходимость соответствия содержания процесса ОК ПП федеральному государственному образовательному стандарту высшего образования (ФГОС ВО) лётной направленности. При этом в процессе обучения ИВС должны выполняться требования о реализации как ФГОС ВО, так и КТ к профессиональной подготовке выпускников - ИВС.

КТ являются дополнением к ФГОС ВО и обязательны для подготовки ИВС по различным родам авиации. В соответствии с требованиями квалификация выпускника лётного вуза ВКС - инженер по лётной эксплуатации летательных аппаратов. В настоящее время принято решение о переходе лётных вузов ВКС с 1 сентября 2021 года на новый ФГОС ВО лётной направленности 3 ++, в котором сокращается количество изучаемых учебных дисциплин с 58 до 42. В связи с этим при формировании основной профессиональной образовательной программы лётным вузам ВКС необходимо определиться, на какие области знания и виды лётной деятельности должен быть ориентирован выпускник - ИВС в соответствии с родом авиации.

Профессиональная деятельность выпускников - ИВС характеризуется: областью применения, объектами, видами, задачами, а также перечнем должностей, которые может замещать выпускник без обучения по программам магистратуры.

Область профессиональной деятельности выпускников - ИВС включает:

- лётную эксплуатацию боевых летательных аппаратов, их силовых установок, комплексов оборудования, вооружения и систем;

- организацию и поддержание в постоянной боевой готовности авиационных подразделений, обеспечение их боевой подготовки;

- руководство экипажами и подразделениями, включая авиационную эскадрилью, в процессе повседневной деятельности, подготовку и ведение боевых действий.

Объектами профессиональной деятельности выпускников - ИВС выступают:

- организация и управление боевой и повседневной деятельностью экипажей и авиационных подразделений;

- органы и средства управления авиацией.

Выпускник - ИВС лётного вуза ВКС может выполнять следующие виды профессиональной деятельности: служебная (боевая и повседневная); военно-педагогическая.

Задачами профессиональной деятельности выпускников - ИВС выступают:

1) служебная (боевая и повседневная) деятельность:

- организация мероприятий по службе войск, укреплению воинской дисциплины и поддержанию уставного порядка, обеспечению необходимых условий жизни и быта подчинённых;

- поготовка на основе выводов из всесторонней оценки обстановки обоснованных решений на выполнение боевых задач;

- планирование мероприятий по выполнению решений командира авиационного подразделения;

2) военно-педагогическая деятельность:

- организация и проведение боевой подготовки с личным составом авиационного подразделения;

- разработка планирующих и методических документов в области военно-профессиональной деятельности;

- контроль профессиональных знаний и навыков лётной подготовки личного состава авиационного подразделения.

Исходя из КТ, выпускник ИВС лётного вуза ВКС без дополнительного обучения по программе магистратуры может замещать офицерские должности в подразделениях и частях национальных военно-воздушных сил до командира эскадрильи включительно.

\section{Основные компоненты и сущность обеспечения качества профессиональной подготовки иностранных военных специалистов в лётных вузах}

Системно-структурный анализ научных источников по теме исследования, ФГОС ВО и КТ лётной направленности позволил выявить основные структурные компоненты ОК ПП ИВС в лётных вузах как педагогического процесса. Основными компонентами ОК ПП ИВС в лётных вузах ВКС как педагогического процесса выступают: обеспечение качества обучения, обеспечение качества воспитания, обеспечение качества психологической подготовки, самосовершенствование ИВС в лётных вузах ВКС, управление педагогическим процессом.

Исходя из состава вышеперечисленных основных компонентов, под сущностью процесса ОК ПП ИВС в лётных вузах ВКС следует понимать обеспечение качественных приоритетов (обучение, воспитание, психологическая подготовка, самосовершенствование, управление), ориентированных на изменяющиеся потребности лётной практики, и их интеграции в вариативную педагогическую среду лётных вузов ВКС. 


\section{Заключение}

Таким образом, мы приходим к следующим выводам. Анализ научных источников, раскрывающих основные понятия, входящие в предметное поле исследования, свидетельствует об иерархической взаимосвязи понятий «подготовка», «деятельность», «профессиональная подготовка» и «обеспечение качества профессиональной подготовки». Системно-структурный метод актуализировал поиск инновационных направлений в исследовании структурно-содержательной характеристики ПП ИВС в лётных вузах. Проанализированные научные источники по теме исследования, ФГОС ВО и КТ лётной направленности позволили обосновать авторский подход к разработке понятий и категорий педагогической теории ОК ПП ИВС в лётных вузах ВКС. Установлена взаимосвязь определяющей категории «обеспечение качества профессиональной подготовки» и категории «профессиональная подготовка». ПП призвана осуществлять формирование интеллектуальноличностных качеств и профессиональных компетенций ИВС, необходимых для эффективной лётной деятельности в авиации национальных Вооруженных Сил. ОК ПП ИВС в лётных вузах ВКС - целенаправленный и организованный процесс инновационного улучшения качественных параметров ПП военного лётчика. Установлены основные особенности ОК ПП ИВС: одновременное функционирование ОК ПП ИВС как составной части педагогической системы вуза и как педагогического процесса; комплексность; многопрофильность и многоплановость; необходимость соответствия содержания процесса ОК ПП ИВС ФГОС ВО и КТ лётной направленности. Выявлены основные компоненты ОК ПП ИВС в лётных вузах как педагогического процесса: ОК обучения; ОК воспитания; ОК психологической подготовки, ОК самосовершенствования ИВС в лётных вузах; ОК управления педагогическим процессом. Установлено, что все компоненты ОК ПП ИВС должны быть структурированы и находиться во взаимосвязи и взаимодействии.

Перспективные направления дальнейших исследований могут быть связаны с разработкой механизма учёта результатов лётной деятельности выпускников - ИВС в авиации национальных армий с целью получения обратной связи для повышения качества профессиональной подготовки ИВС в лётных вузах ВКС.

\section{Источники | References}

1. Алёхин И. А., Кузнецов Ю. Н. Сравнительный историко-педагогический анализ систем обеспечения качества профессиональной подготовки российских офицерских кадров и иностранных военных специалистов // Мир образования - образование в мире. 2017. № 4. С. 69-85.

2. Анохин П. К. Узловые вопросы теории функциональных систем. М.: Наука, 1980. 195 с.

3. Архангельский С. И. Лекции по теории обучения в высшей школе. М.: Высшая школа, 1976. 198 с.

4. Барабанщиков А. В., Давыдов В. П., Конюхов Н. И., Феденко Н. Ф. Методика исследования проблем военной педагогики и психологии: учебное пособие. М.: ВПА, 1987. 48 с.

5. Барабанщиков А. В., Демин В. Г. О закономерностях военно-педагогического процесса. М.: МО РФ, 1967. 67 с.

6. Благодаров А. И. Методологические основы организации системы образования офицерских кадров Вооружённых Сил РФ. М.: МО РФ, 1997. 124 с.

7. Большая советская энциклопедия: в 30-ти т. М.: Советская энциклопедия, 1981. Т. 24. 767 с.

8. Вишнякова С. М. Профессиональное образование: словарь: ключевые понятия и термины, актуальная лексика. М.: Новь, 1999. 535 с.

9. Вопросы психологии и педагогики высшей военной школы / под ред. В. В. Шеляга. М.: Воениздат, 1971. 319 с.

10. Ганзен В. А. Системные описания в психологии. Л.: Изд-во Ленингр. ун-та, 1984. 176 с.

11. Данилов М. А., Малинин В. М. Структурно-системные исследования педагогических явлений и процессов // Советская педагогика. 1971. № 1. С. 21-30.

12. Королёв Ф. Ф. Системный подход и возможности его применения в педагогических исследованиях // Советская педагогика. 1970. № 9. С. 7-19.

13. Краткий словарь терминов военного образования / под общ. ред. Ю. Н. Корякина. М.: Воениздат, 1999. 189 с.

14. Об образовании в Российской Федерации [Электронный ресурс]: Федеральный закон от 29.12.2012 № 273 -Ф3 в редакции от 06.02.2020. URL: https://dokumenty24.ru/zakony-rf/zakon-ob-obrazovanii-v-rf.html (дата обращения: 03.05.2020).

15. Ожегов С. И. Толковый словарь русского языка / под ред. проф. Л. И. Скворцова. Изд-е 28-е, перераб. М.: Мир и образование, 2014. 1376 с.

16. Понятийный аппарат педагогики и образования: сборник научных трудов / отв. ред. Е. В. Ткаченко, М. А. Галагузова. Екатеринбург, 1995. 222 с.

17. Психология: словарь / под ред. А. В. Петровского, М. Г. Ярошевского. Изд-е 2-е, доп. М.: Политиздат, 1990.494 с.

18. Российская педагогическая энциклопедия: в 2-х т. / гл. ред. В. В. Давыдов. М.: Большая Рос. энцикл., 1993. T. 1. A - M. 608 c.

19. Словарь современного русского литературного языка: в 17-ти т. / под ред. В. И. Чернышевского. М. - Л.: Изд-во АН СССР, 1951. Т. 2. 1393 с.

20. Советский энциклопедический словарь. М.: Советская энциклопедия, 1989. 1633 с. 
21. Философский словарь / под ред. И. Т. Фролова. Изд-е 6-е. М.: Республика, 1991. 719 с.

22. Чернилевский Д. В., Морозов А. И. Креативная педагогика и психология: учебное пособие для вузов. М.: Акад. проект, 2004. 559 с.

\section{Информация об авторах | Author information}

RU Кузнецов Юрий Николаевич ${ }^{1}$, к. психол. н.

${ }^{1}$ Военная академия Генерального штаба Вооруженных Сил Российской Федерации, г. Москва

EN Kuznetsov Yuri Nikolaevich ${ }^{1}, \mathrm{PhD}$

${ }^{1}$ Military Academy of the General Staff of the Armed Forces of the Russian Federation, Moscow

${ }^{1}$ kuzznecov1961@yandex.ru

\section{Информация о статье | About this article}

Дата поступления рукописи (received): 02.04.2021; опубликовано (published): 30.06.2021.

Ключевые слова (keywords): понятийно-категориальный аппарат; педагогическая теория; профессиональная подготовка; военные специалисты; лётные вузы Воздушно-космических сил; conceptual-categorial apparatus; pedagogical theory; professional training; military specialists; higher military aviation school. 